\title{
Surface Property of Indium Tin Oxide (ITO) After Various Methods of Cleaning
}

\author{
K. Kim, K. Ihм, B. Kiм* \\ Pohang Accelerator Laboratory, Pohang University of Science \\ and Technology, San 31, Hyojadong, Pohang. Korea
}

\begin{abstract}
We investigated the surface property change of indium tin oxide (ITO) with the various cleaning methods, using photoemission spectroscopy (PES), work function change and near-edge X-ray adsorption fine structure (NEXAFS). The detergent treatments of ITO with acetone $\left(\mathrm{C}_{3} \mathrm{H}_{6} \mathrm{O}\right)$, methanol $\left(\mathrm{CH}_{4} \mathrm{O}\right)$, 2-propanol $\left(\mathrm{C}_{3} \mathrm{H}_{8} \mathrm{O}\right)$, and deionized (D) water yielded work function shifts as high as $0.99 \mathrm{eV}$ compared to the no-treatment ITO. In contrast, work function shifts of $0.10-0.35 \mathrm{eV}$ were measured after other treatments. The lowest $\mathrm{C}$ 1s concentration was obtained after $\mathrm{O} 2$ plasma treatment of ITO. There was no big change in the peak position and the shape of In $3 \mathrm{~d}^{5 / 2}$, and $\mathrm{Sn} 3 \mathrm{~d}^{5 / 2}$ after each treatment. But $\mathrm{C}$ 1s and $\mathrm{O} 1 \mathrm{~s}$ spectra shows a peak shift and shape change. Presence of carbon can be minimized by $\mathrm{NaOH}$ treatment combined with oxygen plasma. In NEXAFS spectra of $\mathrm{C}$ K-edge on each sample, we found two $\pi$-binding states whose positions are 284.5 and $287.9 \mathrm{eV}, \mathrm{C}=\mathrm{C}$ and $\mathrm{C}=\mathrm{O}$, respectively.
\end{abstract}

DOI: 10.12693/APhysPolA.127.1176

PACS: 73.20.-r Electron states at surfaces and interfaces

\section{Introduction}

Indium tin oxide (ITO, $\mathrm{In}_{2} \mathrm{O}_{3}: \mathrm{Sn}$ ) as a transparent conductive film (TCFs), is an important material in the construction of optical devices, including organic light emitting diode (OLED)s, liquid crystal displays (LCD), and solar cells because of its transparency and high conductivity. In organic electro-luminescence devices, ITO is used as an anode or a hole-injecting electrode based on its work function. And, it has been known that the work function of such devices is extremely sensitive to the state of the ITO surface, and that the surface properties of the ITO affect the electro and photo-luminescence characteristics of the OLEDs $[1,2]$, and the optical transmittance of the ITO film [3]. It was shown that different effects occurred when different surface treatment methods of ITO were applied in the organic light-emitting diode [4]. But, the advent of the flexible, wearable or stretchable versions of optoelectronic devices, are opening a new developing trend and application. So, considering the advancements in optoelectronic devices, it is well known that ITO has several limitations such as: an expensive cost, the complex preparation methods, the lack of flexibility as it cracks easily, the diffusion of indium into the active layers of OLEDs or OPV cells, etc. Therefore, in recent years there has been a rapid growth in the development of ITO alternatives based on carbon nanotube (CNTs), graphene, and conducting polymers, etc.s [5]. But, yet, ITO is the most widely used TCF because of its excellent opto-electrical properties. Although many studies reported modifying the surface properties

* corresponding author; e-mail: kbs007@postech.ac.kr of ITO by various methods, including chemical process (degreasing and RCA protocol) and physical treatments using oxygen plasma and Ar ion sputtering [6-8], the oxygen plasma has been considered a promising method because it results in the highest work function, the lowest sheet resistance, and the smoothest surface [9]. However, there is a problem of the oxygen concentration increasing after oxygen plasma treatment. It has been reported that the presence of carbon on the ITO surface [10] degraded the device performance and the removal of the organic residue from the ITO surface by oxygen plasma treatment could lead to the device improvement. In this study, we examined the changes in the surface propertise correlated with the work function and surface chemical composition of ITO using photoemission spectroscopy (PES) [11], near edge X-ray adsorption fine structure (NEXAFS), and work function measurements.

\section{Experiments}

The substrates used in this study were glass coated with $150 \mathrm{~nm}$ thick ITO having a sheet resistivity of $19 \Omega / \mathrm{cm}^{2}$. We prepared 5 samples for this experiment to compare the effects of cleaning methods. The ITO substrates were ultrasonically cleaned in detergent for about $5 \mathrm{~min}$, followed by a thorough rinse in de-ionized water. They were, then, dipped in $\mathrm{NaOH}$ solution $(0.05 \mathrm{M})$ for 1 hour for $\mathrm{NaOH}$ treatment. For plasma treatments, the substrates were exposed to oxygen-plasma in a reactive ion etching system. The summary of the preparation method of each ITO surface is shown in Table I.

PES and NEXAFS measurements were performed at the 2B1 (spherical grating monochromator) beamline $[12,13]$ at the PLS (Pohang Light Source) storage ring [14]. The electric field vector of the synchrotron was on the same plane as the electron analyzer, and the photons were impinged on the surface at $45^{\circ}$ with respect 
Summary of ITO surface treatments.

TABLE I

\begin{tabular}{c|c}
\hline \hline Sample & Surface treatment \\
\hline 0 & No treatment, as grown \\
\hline 1 & $\begin{array}{c}\text { Detergent treatment, Sonication in Acetone, } \\
\text { Methanol, 2-propanol and DI water }\end{array}$ \\
& 5 minute at each step followed by DI water rinsing \\
\hline 2 & NaOH treatment, \\
& Sonication in NaOH $(0.05 \mathrm{M})$ \\
& 1 Hour after \#1 procedure \\
\hline 3 & $\mathrm{O}_{2}$ plasma treatment, \\
& Exposed to $\mathrm{O}_{2}$ plasma \\
& 5 min after \#1 procedure \\
\hline 4 & $\mathrm{O}_{2}$ plasma $+\mathrm{NaOH}$ \\
& Sonication in NaOH $(0.05 \mathrm{M})$ \\
& 1 Hour after \#1 and \#2 procedure
\end{tabular}

to the surface normal. The $\mathrm{O} 1 \mathrm{~s}$, Sn $3 \mathrm{~d}^{5 / 2}$, In $3 \mathrm{~d}^{5 / 2}$, and $\mathrm{C}$ 1s core level spectra were taken with the photon energy of $650 \mathrm{eV}$. The spectral resolution was $400 \mathrm{meV}$ for core level spectra. The $\mathrm{Au} 4 \mathrm{f}^{7 / 2}$ core level of sputtered $\mathrm{Au}$ film was used to calibrate the binding energy of each core level and the spectral resolution. The cutoff of the secondary electron tail of the photoemission spectrum was measured while applying a bias voltage ($20 \mathrm{~V}$ ) to the sample for measuring work function change. The NEXAFS spectra were obtained using total electron yield detected by the drain current from the sample. Every spectra was measured at the incident photon angle of $55^{\circ}$ which is called a magic angle. The photons had a degree of polarization of about $85 \%$. The spectra were normalized to the incident photon flux by a spectrum of a clean gold reference grid measured simultaneously. The photon resolution was $350 \mathrm{meV}$ near the carbon K-edge region.

\section{Results and discussion}

Figure 1 shows the PES spectra of O $1 \mathrm{~s}, \mathrm{C} 1 \mathrm{~s}, \mathrm{In} 3 \mathrm{~d}^{5 / 2}$, and $\mathrm{Sn} 3 \mathrm{~d}^{5 / 2}$ core level. In Fig. 1a, O 1s peak was consisting of 3 components. Each peak is originated from $\mathrm{In}_{2} \mathrm{O}_{3}$, $\mathrm{SnO}_{2}$ and $\mathrm{C}-\mathrm{O}$ (carbonate). On the as-grown sample (sample 0), the carbonate peak is comparable with $\operatorname{In}_{2} \mathrm{O}_{3}$. The peak was decreased after detergent treatment on the sample 1. After $\mathrm{NaOH}$ treatment (sample 2) the peak height of $\mathrm{In}_{2} \mathrm{O}_{3}$ and $\mathrm{SnO}_{2}$ were increased a little bit, but the carbonate was similar as sample 1. Oxygen plasma treatments resulted in increasing the peak height of the $\mathrm{In}_{2} \mathrm{O}_{3}$ and $\mathrm{SnO}_{2}$, but still carbonate remains. The carbonate peak was negligible when it was treated with $\mathrm{NaOH}$ after oxygen plasma treatment. Figure 1b shows $\mathrm{C}$ 1s core-level spectra. It consists from 3 peaks, C-C, $\mathrm{C}-\mathrm{O}$, and $C=O$, respectively. On sample $0, \mathrm{C}-\mathrm{C}, \mathrm{C}-$ $\mathrm{O}$ and $\mathrm{C}=\mathrm{O}$ were relatively high. After detergent, oxygen plasma and $\mathrm{NaOH}$ treatments the intensity of $\mathrm{C}-\mathrm{C}$ and $\mathrm{C}-\mathrm{O}$ peaks were decreased. $\mathrm{C}=\mathrm{O}$ remains as similar trace. Sample 2 shows decreased peak height, but it still contains $\mathrm{C}-\mathrm{O}$ related features. On sample 3 , the relative intensity of $\mathrm{C} 1 \mathrm{~s}$ was decreased after oxygen plasma treatment. When $\mathrm{NaOH}$ and oxygen plasma treatment was combined, the peak height of $\mathrm{C}$ 1s was the smallest one and carbonate related component became negligent on sample 4. This means that $\mathrm{C}-\mathrm{O}$ related components can be removed effectively through $\mathrm{NaOH}$ treatment after oxygen plasma. This is in consistence with $\mathrm{O}$ 1s corelevel. And the intensity of In $3 \mathrm{~d}^{5 / 2}$ and Sn $3 \mathrm{~d}^{5 / 2}$ corelevel were increased after each treatment. But, after the oxygen plasma treatments, as can be seen in Fig. 1c and $\mathrm{d}$, the intensity of In $3 \mathrm{~d}^{5 / 2}$ and Sn $3 \mathrm{~d}^{5 / 2}$ were enhanced. Because the oxygen plasma treatment has contributed to reduce carbon related species on the surface, carbon was removed and In $3 \mathrm{~d}^{5 / 2}$ and $\mathrm{Sn} 3 \mathrm{~d}^{5 / 2}$ become major components on the surface. This is also in accordance with $\mathrm{O} 1 \mathrm{~s}$ and $\mathrm{C} 1 \mathrm{~s}$ results.

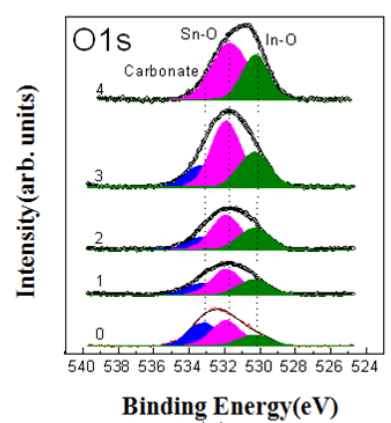

(a)

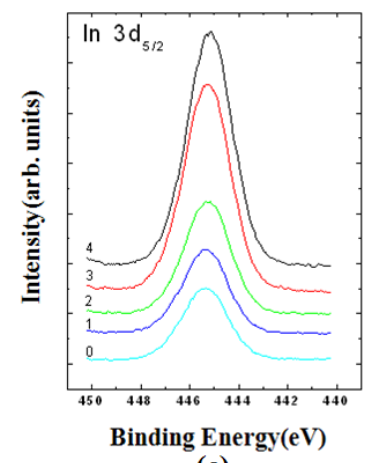

(c)

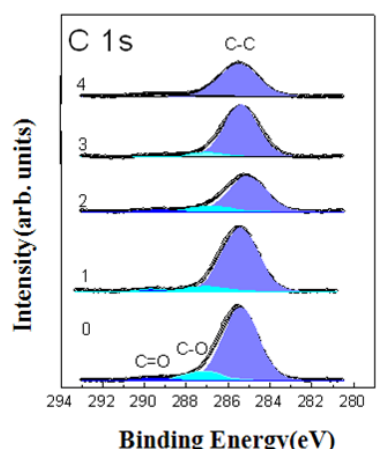

(b)

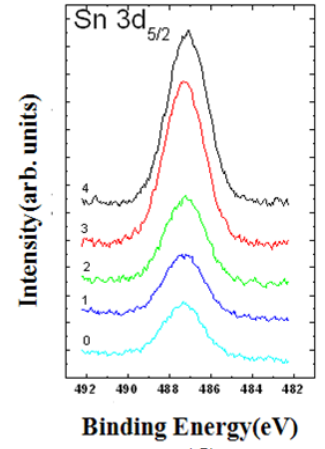

(d)
Fig. 1. PES spectra of O $1 \mathrm{~s}$ (a), C $1 \mathrm{~s}$ (b), In $3 \mathrm{~d}^{5 / 2}$ (c), and $\mathrm{Sn} 3 \mathrm{~d}^{5 / 2}$ (d) core level. Each ample number was appeared on the left side of spectrum.

The chemical composition change and the work function shift after the various treatments were summarized in table II. Sample 1 and Sample 2 maintained a similar surface components ratio. Oxygen plasma treatment (sample 3 ) shows a decreased $\mathrm{C} 1 \mathrm{~s}$ ratio and an increased In $3 \mathrm{~d}^{5 / 2}$ ratio. The ratio of $\mathrm{C} 1 \mathrm{~s}$ and $\mathrm{In} 3 \mathrm{~d}^{5 / 2}$ changed in accordance with the treatment conditions. There was an increase in $\mathrm{O}$ 1s after the oxygen plasma treatment. The $\mathrm{O}$ 1s intensity decreased again after $\mathrm{NaOH}$ treatments. However, the ratio of $\mathrm{Sn} 3 \mathrm{~d}^{5 / 2}$ was not changed. The work function change was the biggest on the detergent treated surface (sample 1) with $0.99 \mathrm{eV}$-increased values. This means that the adsorbed contaminant layers in sample 1 acted as a charge transfer layer. After $\mathrm{NaOH}$ treatments (sample 2), the work function became $0.1 \mathrm{eV}$. On the Oxygen plasma treated (sample 3) surface, the 
work function increased to $0.35 \mathrm{eV}$, and it decreased to $0.19 \mathrm{eV}$ after $\mathrm{NaOH}$ treatment (sample 4). In general, $\mathrm{NaOH}$ treatment induced a decrease in the work function.

Work function change $(\mathrm{eV})$ and

TABLE II Chemical composition (\%).

\begin{tabular}{c|c|c|c|c|c}
\hline \hline Sample & $\Delta \varphi$ & O 1s & C 1s & Sn 3d $^{5 / 2}$ & In 3d $^{5 / 2}$ \\
\hline 0 & 0 & 17.9 & 48.9 & 5.8 & 28.4 \\
1 & 0.99 & 20.0 & 29.3 & 7.3 & 43.3 \\
2 & 0.1 & 18.9 & 31.5 & 7.5 & 42.1 \\
3 & 0.35 & 23.0 & 16.0 & 9.8 & 51.2 \\
4 & 0.19 & 19.4 & 22.4 & 8.4 & 49.8
\end{tabular}

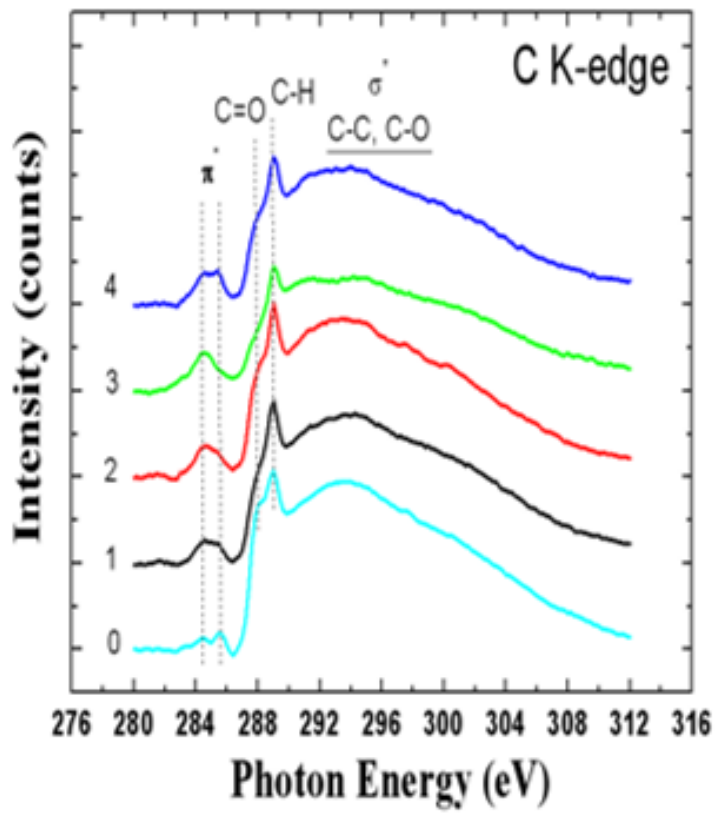

Fig. 2. NEXAFS spectra of C K-edge. After each cleaning, $\mathrm{C}=\mathrm{O}$ bond was effectively reduced.

The molecular structures of the carbon contamination on the surface were investigated through NEXAFS. Figure 2 shows the NEXAFS spectra of C K-edge. Several featured peaks were observed. The first peak is the wellknown $\mathrm{C}=\mathrm{C} \pi^{*}$ resonance around $284.5 \mathrm{eV}$. The second peak was $\mathrm{C}=\mathrm{O} \pi^{*}(287.9 \mathrm{eV}) . \mathrm{C}-\mathrm{H} \pi^{*}(289 \mathrm{eV})$ also appeared. The broad peak, centered at $294 \mathrm{eV}$, is regarded as $\mathrm{C}-\mathrm{H}, \mathrm{C}-\mathrm{C}$, and $\mathrm{C}-\mathrm{O} \sigma^{*}$. In non-treatment sample, an explicit double peak was observed at low photon energy. The peak $\mathrm{C}=\mathrm{O} \pi^{*}$ decreased in sample 1 while in sample 3 , the adsorbed spectral intensity of $\mathrm{C}$ K-edge was the smallest and the $\mathrm{C}=\mathrm{O} \pi^{*}$ was negligible. This means that the carbon contaminants can be reduced effectively by oxygen plasma treatment. The $\mathrm{C}=\mathrm{O} \pi^{*}$ was increased again after $\mathrm{NaOH}$ treatment. But its intensity was negligible. In accordance with $\mathrm{C}$ 1s core level spectra in Fig. 1, carbon-related species were effectively decreased after $\mathrm{NaOH}$ treatments. We compare the surface composition change after the oxygen plasma treatment (sample

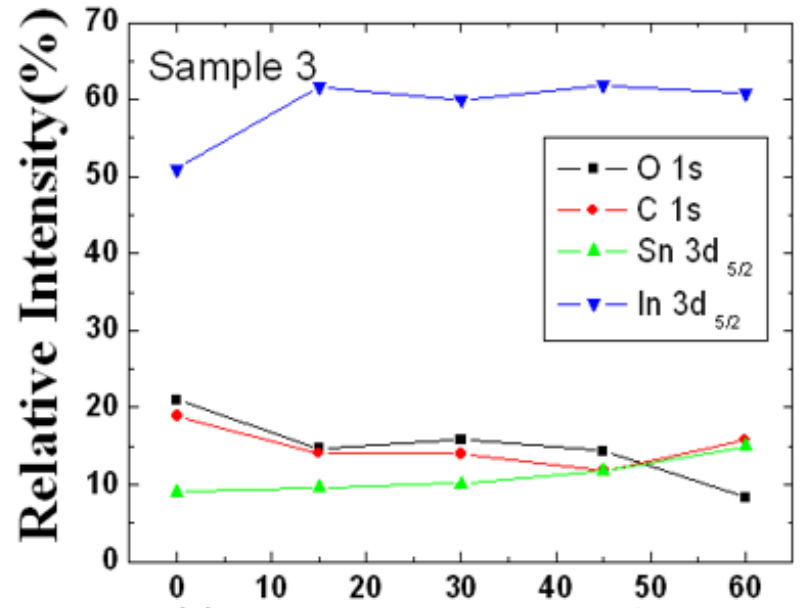

(a) Emission Angle $\left({ }^{\circ}\right)$

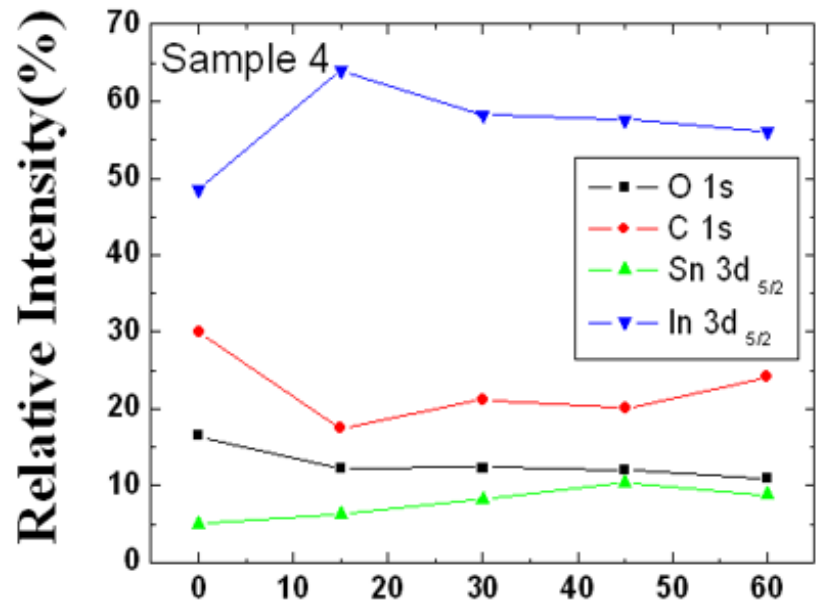

(b) Emission Angle $\left({ }^{0}\right)$

Fig. 3. Relative intensity ratio change of $\mathrm{O} 1 \mathrm{~s}$, Sn $3 \mathrm{~d}^{5 / 2}$, In $3 \mathrm{~d}^{5 / 2}$, and $\mathrm{C} 1 \mathrm{~s}$ core level depending on the emission angle in samples 3 (a) and 4 (b).

3) and $\mathrm{NaOH}$ treatment after oxygen plasma treatments (sample 4).

Even though the oxygen plasma treatment effectively reduces the carbon related species, the work function change was $350 \mathrm{meV}$ but, the value was decreased to $190 \mathrm{meV}$ after $\mathrm{NaOH}$ treatment. So, we measured O 1s, Sn $3 \mathrm{~d}^{5 / 2}$, In $3 \mathrm{~d}^{5 / 2}$, and C 1 s core level upon the photoelectron emission angle to trace outermost components. Figure 3 shows a relative intensity ratio change of $\mathrm{O} 1 \mathrm{~s}$, Sn $3 \mathrm{~d}^{5 / 2}$, In $3 \mathrm{~d}^{5 / 2}$, and $\mathrm{C} 1 \mathrm{~s}$ core level depending on the emission angle of samples 3 and 4 . O 1s concentration is similar in both samples. The $\mathrm{C}$ concentration in sample 4 is higher than in sample 3. C 1s doesn't show angle dependence on both samples. As the surface sensitivity increased, the intensity of the $\mathrm{Sn} 3 \mathrm{~d}^{5 / 2}$ increased in sample 3 and sample 4 . But, Sn $3 \mathrm{~d}^{5 / 2}$ is minor species on sample 4 . We estimated the thickness of the carbon-contaminated layer to be 3.31 and $4.47 \AA$ on 
sample 3 and 4 using the elastic mean free path (IMFP) of electron measurements and intensity ratio of $\mathrm{C} 1 \mathrm{~s}$ and In $3 \mathrm{~d}^{5 / 2}[10,11]$.

\section{Conclusions}

The surface properties of indium tin oxide (ITO) after various methods of cleaning were investigated using photoemission spectroscopy, work function change, and near-edge X-ray adsorption fine structure measurements. Our experiments revealed that the cleaning methods could modify the surface composition on the ITO surface. $\mathrm{NaOH}$ treatment after oxygen plasma effectively removed carbonate features. The lowest $\mathrm{C} 1 \mathrm{~s}$ concentration was obtained on $\mathrm{O}_{2}$ plasma-treated ITO. The detergent treatment show $0.9 \mathrm{eV}$ increas in work function higher than that of non-treated ITO. There is a work function decrease after $\mathrm{NaOH}$ treatment to $0.1 \mathrm{eV}$. The oxygen plasma treatment show work function $0.35 \mathrm{eV}$ higher than the non-treated ITO. It also shows the work function decrease after $\mathrm{NaOH}$ treatment to $0.19 \mathrm{eV}$. Therefore, $\mathrm{NaOH}$ treatments mediated the decrease of the work function as well as the reducing carbon species.

\section{Acknowledgments}

The experiments at PLS were supported in part by MEST and POSTECH. This research was supported by the National Research Foundation of Korea funded by the Ministry of Education, Science and Technology (2010_0008608, 2009-0087138, and NSFC-NRF Scientific Cooperation Program (2012.07 2014.06), and NRF2013R1A1A-2006949).

\section{References}

[1] C.C. Wu, C. Wu, J.C. Sturm, A. Kahn, Appl. Phys. Lett. 70, 1348 (1997).

[2] M.F. Lo, T.W. Ng, H.W. Mo, C.S. Lee, Adv. Func. Mater. 23, 1718 (2013).

[3] Y.S. Park, E. Kim, B. Hong, J. Lee, Mater. Res. Bull. 48, 5115 (2013).

[4] S. Jung, N.G. Park, M.Y. Kwak, B.O. Kim, K.H. Choi, Y.J. Cho, Y.K. Kim, Y.S. Kim, Opt. Mater. 21, 235 (2003).

[5] Z. He, H. Wu, Y. Cao, Adv. Mater. 26, 1006 (2014).

[6] D. Lu, Y. Wu, J. Guo, G. Lu, Y. Wang, J. Shen, Mater. Sci. Eng. B 97, 141 (2003).

[7] K. Sugiyama, H. Ishii, Y. Ouchi, J. Appl. Phys. 87, 295 (2000).

[8] S.K. So, W.K. Choi, C.H. Cheng, L.M. Leung, C.F. Kwong, Appl. Phys. A 68, 447 (1999).

[9] J.S. Kim, R.H. Friend, F. Cacialli, Appl. Phys. Lett. 74, 3084 (1999).

[10] C.C. Wu, C.I. Wu, J.C. Strum, A. Kahn, Appl. Phys. Lett. 70, 1348 (1997).

[11] H. Yamamoto, Y. Baba, T.A. Sasaki, Surf. Sci. 349, L133 (1996).
[12] S. Rah, T. Kang, Y. Chung, B. Kim, K. Lee, Rev. Sci. Instrum. 66, 1751. (1995).

[13] K.J Kim, T.H. Kang, B. Kim, J. Kor. Phys. Soc. 30, 148 (1997).

[14] I.S. Ko, J.Y. Huang, D.K. Seon, C.B. Kim, T.-Y. Lee, J. Kor. Phys. Soc. 35, 411 (1999). 